\title{
Massive bleeding from a rectal Dieulafoy lesion in a patient with alcoholic cirrhosis
}

\author{
Young Hoon Choi, Jong Ryeol Eun, Jae Ho Han, Hyun Lim, Jung A Shin, Gun Hwa Lee, \\ Seung Hee Lee
}

Department of Internal Medicine, Myongji Hospital, Seonam Univeristy College of Medicine, Goyang, Korea

\begin{abstract}
Although Dieulafoy lesion can occur in any part of the gastrointestinal tract, its occurrence in the rectum is rare. Rectal Dieulafoy lesions have been associated with advanced age, renal failure, burns, liver transplantation and cirrhosis. Here, we report on a case of massive bleeding from a rectal Dieulafoy lesion after lung decortication surgery in a 57-year-old male patient with alcoholic cirrhosis. Although rare, a rectal Dieulafoy lesion should be included in the differential diagnosis of massive lower gastrointestinal bleeding in a patient with cirrhosis.
\end{abstract}

Keywords: Dieulafoy lesion; Rectum; Liver cirrhosis

\section{INTRODUCTION}

Many types of gastrointestinal (GI) bleeding can occur in cirrhotic patients, however, the most common type is upper GI bleeding due to variceal rupture or ulcer [1]. Variceal bleeding represents $60-65 \%$ of the bleeding episodes in cirrhotic patients [2]. Common causes of lower GI bleeding include diverticular disease, neoplasms, angiodysplasia, hemorrhoids, and polyps, accounting for more than $95 \%$ of cases [3].

Dieulafoy lesion, a submucosal artery that protrudes through a small mucosal defect into the lumen, is a life-threatening cause of GI bleeding. Although it can occur in any part of the GI tract, the stomach is the most common location, accounting for approximately $71 \%$ of cases and it is very rare in the rectum [4]. Bleeding due to a rectal Dieulafoy lesion

Received: August 8, 2015, Revised: September 21, 2015 Accepted: September 30, 2015

Corresponding Author: Jong Ryeol Eun, Department of Internal Medicine, Myongji Hospital, Seonam University College of Medicine, 55 Hwasu-ro 14beon-gil, Deokyang-gu, Goyang 10475, Korea Tel: +82-31-810-5114, Fax: +82-31-969-0500

E-mail: dreundavis@gmail.com has been reported sporadically in many medical conditions including one case of alcoholic cirrhosis in Korea [4-10].

We report on a case of massive bleeding from a rectal Dieulafoy lesion in a patient with alcoholic cirrhosis.

\section{CASE}

A 57-year-old male patient with alcoholic cirrhosis was rushed to the emergency room complaining of shortness of breath. He underwent chest tube insertion due to large lung empyema (Fig. 1A, 1B) and received ventilator care. His bowel movement was unremarkable without constipation. On the 26th day after admission, he underwent decortication surgery because of intractable empyema. At that time, his body mass index was 17.7 (height $173 \mathrm{~cm}$, weight $53 \mathrm{~kg}$ ), his vital signs included a blood pressure (BP) of $127 / 90 \mathrm{mmHg}$ and a heart rate of 97 beats per minute. His laboratory findings were as follows: white blood cell (WBC) count, 8,500/ $\mathrm{L}$; hemoglobin $(\mathrm{Hb}), 9.4 \mathrm{~g} / \mathrm{dL}$, hematocrit, 28\%; platelet count, 92,000/ $\mathrm{LL}$; total/direct bilirubin, 2.8/1.6 (mg/dL); aspartate aminotransferase (AST), $38 \mathrm{IU} / \mathrm{L}$; alanine aminotransferase (ALT), $13 \mathrm{IU} / \mathrm{L}$; and prothrombin time, $18.1 \sec (56 \%)$; HBsAg (-), HBsAb (-),

Copyright (C) 2017 Yeungnam University College of Medicine

This is an Open Access article distributed under the terms of the Creative Commons Attribution Non-Commercial License (http://creativecommons.org/licenses/by-nc/4.0/) which permits unrestricted non-commercial use, distribution, and reproduction in any medium, provided the original work is properly cited. 

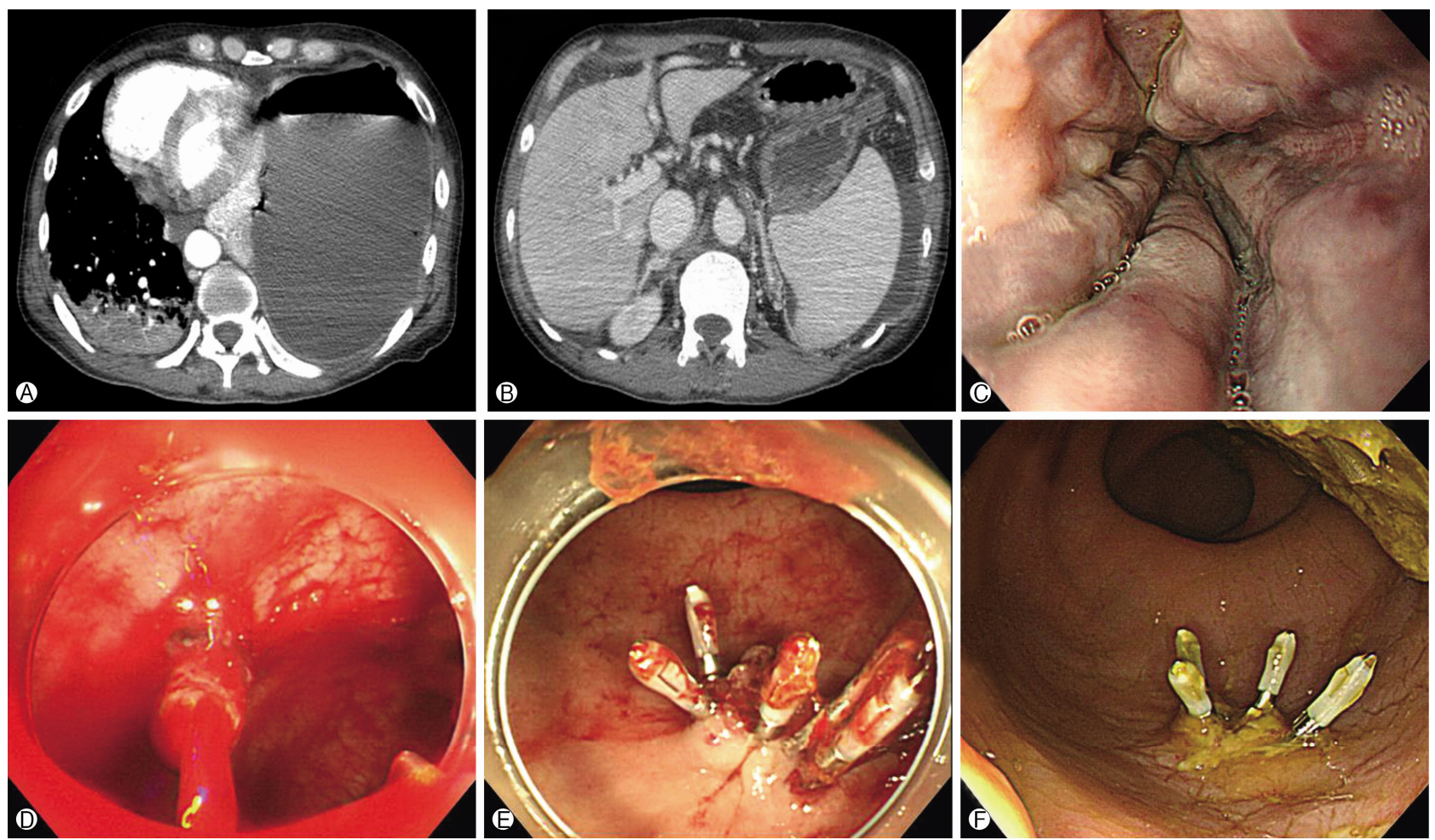

Fig. 1. (A, B) Computed tomography showed a large lung empyema displacing the heart and cirrhotic liver with ascites. (C) Upper en doscopy showed large esophageal varices. (D) Fresh blood was gushing from a large exposed blood vessel in the distal rectum. (E) Active bleeding was controlled using hemoclips (HX-610-090L, Olympus, Tokyo, Japan). (F) Two days later, the hemoclips were correctly placed.

anti-HCV (-). On the 8th day after surgery, painless hematochezia occurred. At that time, his BP dropped to $67 / 45 \mathrm{mmHg}$ and heart rate increased to 108 beats per minute. His laboratory findings were as follows: WBC count, $12,600 / \mu \mathrm{L} ; \mathrm{Hb}$, $7.8 \mathrm{~g} / \mathrm{dL}$; platelet count, 126,000/ $\mu \mathrm{L}$; albumin, $2.7 \mathrm{~g} / \mathrm{dL}$; total/ direct bilirubin 2.7/1.3 (mg/dL); AST/ALT, 30/11 (IU/L); BUN/ Creatinine 12.8/0.5 (mg/dL). Emergency sigmoidoscopy was performed. However, we failed to find the bleeding focus because of a large amount of stool in the rectum and a large amount of fresh blood in the sigmoid colon. Hence, we considered that the bleeding focus was within the proximal part of the sigmoid colon. Upper endoscopy showed large esophageal varices and portal hypertensive gastropathy, but no evidence of bleeding (Fig. 1C). He received conservative care including transfusion. Hematochezia stopped transiently, but the next day, massive hematochezia started again. Despite administration of 10 units of packed red blood cells and 6 units of fresh frozen plasma, his systolic BP was $60 \mathrm{mmHg}$ and $\mathrm{Hb}$ was $6.3 \mathrm{~g} / \mathrm{dL}$. Emergency sigmoidoscopy was performed again.
At first, finding the bleeding focus was difficult because there was still a large amount of stool. However, that the amount of fresh blood had decreased. We withdrew the scope back into the rectum and searched the area meticulously. After changing to the right lateral decubitus position, we finally observed blood gushing from a large exposed blood vessel (Fig. 1D). The bleeding was controlled successfully using hemoclips (HX-610090L, Olympus, Tokyo, Japan) (Fig. 1E). He became hemodynamically stable after the procedure. Two days later, the hemoclips were correctly placed and no further bleeding occurred (Fig. 1F). He was discharged from the hospital with relatively good health.

\section{DISCUSSION}

In this case, the patient had underlying alcoholic liver cirrhosis and he underwent lung decortication surgery due to intractable empyema. Occurrence of a rectal Dieulafoy lesion in this patient is difficult to explain. It might have occurred 
coincidentally because Dieulafoy lesion itself has so far been regarded as congenital pathology [11], however, it may be multifactorial.

Most cases of rectal Dieulafoy lesions have been reported in patients with multiple comorbidities like advanced age [4-6], renal failure [7], burns [8], and liver transplantation [9]. In Korea, one case was reported for alcoholic cirrhosis [10].

Mucosa of a large artery is vulnerable to mechanical trauma and tissue ischemia from repeated strong pulsation leading to mucosal ulceration [11,12]. Macroscopically, the lesion was bulging into the lumen of the GI tract with predilection for mechanical trauma [13].

Perivascular tissue ischemia and degenerative changes may precipitate the rupture of a congenitally deformed submucosal artery [11]. In this case the patient had medical conditions including alcoholic cirrhosis and lung empyema. Therefore, we postulate that acquired tissue ischemia might have precipitated the rupture of an underlying congenital large submucosal artery.

With respect to diagnosis and treatment, we initially did not consider Dieulafoy lesion as a differential diagnosis. Instead, we considered upper GI bleeding such as variceal or ulcer bleeding. After ruling out upper GI bleeding, we considered lower GI bleeding from a diverticulum or angiodysplasia, etc.

Finding the bleeding focus was difficult because of poor visibility. In the previous study, the main reasons for unsuccessful initial endoscopy were excessive blood (44\%) and the lesions were subtle or overlooked (56\%) [14].

On the second try, we suspected rectal bleeding because the amount of blood decreased as the scope was advanced up to the sigmoid colon. Hence, we withdrew the scope and searched the rectum meticulously. Finally, we found the active bleeding focus after changing to the right lateral decubitus position. We were able to control the bleeding successfully using hemoclips and no bleeding occurred thereafter. Endoscopic treatment is currently considered the first option for management of GI Dieulafoy lesions [7].

Although rare, a rectal Dieulafoy lesion should be included in the differential diagnosis of massive GI bleeding in a patient with cirrhosis.

\section{CONFLICT OF INTEREST}

No potential conflict of interest relevant to this article was reported.

\section{REFERENCES}

1. Cremers I, Ribeiro S. Management of variceal and nonvariceal upper gastrointestinal bleeding in patients with cirrhosis. Therap Adv Gastroenterol 2014;7:206-16.

2. Garcia-Tsao G, Sanyal AJ, Grace ND, Carey W; Practice Guidelines Committee of the American Association for the Study of Liver Diseases; Practice Parameters Committee of the American College of Gastroenterology. Prevention and management of gastroesophageal varices and variceal hemorrhage in cirrhosis. Hepatology 2007;46:922-38.

3. Harrison JD, Calatayud A, Thava VR, Kirby RM. Massive arterial bleeding from a single rectal vessel. Postgrad Med J 1997;73:303-4.

4. Lee YT, Walmsley RS, Leong RW, Sung JJ. Dieulafoy's lesion. Gastrointest Endosc 2003;58:236-43.

5. Kim HH, Kim JH, Kim SE, Park SJ, Park MI, Moon W. Rectal dieulafoy lesion managed by hemostatic clips. J Clin Med Res 2012;4:439-41.

6. Kim M, Song HJ, Kim S, Cho YK, Kim HU, Song BC, et al. Massive life-threatening lower gastrointestinal hemorrhage caused by an internal hemorrhoid in a patient receiving antiplatelet therapy: a case report. Korean J Gastroenterol 2012; 60:253-7.

7. Gimeno-García AZ, Parra-Blanco A, Nicolás-Pérez D, Ortega Sánchez JA, Medina C, Quintero E. Management of colonic Dieulafoy lesions with endoscopic mechanical techniques: report of two cases. Dis Colon Rectum 2004;47:1539-43.

8. Guy RJ, Ang ES, Tan KC, Tsang CB. Massive bleeding from a Dieulafoy-like lesion of the rectum in a burns patient. Burns 2001;27:767-9.

9. Apiratpracha W, Ho JK, Powell JJ, Yoshida EM. Acute lower gastrointestinal bleeding from a dieulafoy lesion proximal to the anorectal junction post-orthotopic liver transplant. World J Gastroenterol 2006;12:7547-8.

10. Park SH, Lee MH, Kim HS, Lee JW, Kim SJ, Chung IK, et al. A Dieulafoy-like lesion of the rectum as a cause of massive lower G-I bleeding. Korean J Gastrointest Endosc 1999;19: 454-9. Korean.

11. Treesaranuwattana S, Khemtai C. Dieulafoy's lesion: pathology, diagnosis and treatment. Thai J Surg 2002;23:87-96.

12. Bakka A, Rosseland AR. Massive gastric bleeding from exulceratio simplex (Dieulafoy). Acta Chir Scand 1986;152: 285-8.

13. Juler GL, Labitzke HG, Lamb R, Allen R. The pathogenesis of Dieulafoy's gastric erosion. Am J Gastroenterol 1984;79: 195-200.

14. Baxter M, Aly EH. Dieulafoy's lesion: current trends in diagnosis and management. Ann R Coll Surg Engl 2010;92:548-54. 